Article

\title{
The Relationship between Technology Use and Physical Activity among Typically-Developing Children
}

\author{
Thekra Alotaibi ${ }^{1}$, Rifan Almuhanna ${ }^{1}$, Johara Alhassan ${ }^{1}$, Ethar Alqadhib ${ }^{1}$, Eman Mortada ${ }^{2}$ and \\ Reem Alwhaibi 1,*(D) \\ 1 Rehabilitation Sciences Department, College of Health and Rehabilitation Sciences, Princess Nourah Bint \\ Abdulrahman University, Riyadh 11466, Saudi Arabia; thekra_alotaibi@hotmail.com (T.A.); \\ Rifan.Almuhanna@gmail.com (R.A.); johara-alhassan@hotmail.com (J.A.); ethar.m.q@gmail.com (E.A.) \\ 2 Health Sciences Department, College of Health and Rehabilitation Sciences, Princess Nourah Bint \\ Abdulrahman University, Riyadh 11466, Saudi Arabia; EMMortada@pnu.edu.sa \\ * Correspondence: rmalwhaibi@pnu.edu.sa
}

Received: 3 October 2020; Accepted: 9 November 2020; Published: 17 November 2020

\begin{abstract}
Objectives: This study aimed to investigate the relationship between technology use and physical activity level and to measure the association between sociodemographic characteristics of the participants, technology use, and physical activity level among Saudi children. Materials and Methods: This cross-sectional study was conducted among 458 parents of typically-developing Saudi children (6-12 years). A translated validated questionnaire used for data collection consisted of three parts: Children's Physical Activity Questionnaire (CPAQ), Questionnaire on the Impact of Technology on Children (used to investigate the impact of technology on children's physical activity) and sociodemographic questions (e.g, children's age and sex, age, educational level, marital status of parents and monthly income). Data were analyzed using Pearson correlation and Mann-Whitney $\mathrm{U}$ test to assess the relationship between technology use and physical activity level. A chi-squared test was used to assess the relationship between technology use and sociodemographic variables. Statistical significance was set at $p<0.05$. Results: Mean age of the sampled children was $(8.44 \pm 2.07)$. Data analysis revealed that high use of technology was significantly associated with low level of activity. Pearson's correlation analysis showed a negative relationship between a high level of activity and technology use $(r=-0.138, p=0.047)$. Ownership of a device was significantly associated with higher technology time consumption. Regression analysis revealed that age of the child, educational level of the parents, screen time use, and owning electrical devices significantly predicted the level of practicing physical activity among children of sampled parents $(p<0.05)$. Conclusions: practicing inadequate physical activity among children could be influenced by educational level of parents, screen time use, and owning electrical devices. Therefore, parental involvement is required to reduce time of exposure to technology screens among children.
\end{abstract}

Keywords: physical activity; youth; technology use; parents' questionnaire; children

\section{Introduction}

Children are increasingly attracted to the newest forms of technology [1]. With the recent rise in popularity of smart phones and tablets, the use of such technological devices has become unavoidable and is now viewed as an integral part of life. According to the General Authority of Statistics (GAS) in Saudi Arabia, 98.44\%, 61.08\%, 83.87\%, and $47.21 \%$ of households or families have televisions, use computers, are internet users, or own smart devices, respectively [2]. 
Technology use is associated with increased risk of obesity in children [3], type 2 diabetes mellitus, and all-cause mortality [4]. It has also been associated with increased risk of metabolic syndrome [5], and a large range of physical and psychological disorders seen in technology-dependent children [6]. Technology-dependent children tend to have impaired quality of life and are often affected emotionally, socially, and academically [7,8]. Increased dependency on technology was associated with increased level of anxiety symptoms, depression, aggression, and attention and behavioral problems [9]. It was also associated with lower academic performance, Grade Point Average (GPA), language, math and reading achievements $[9,10]$. Furthermore, increased screen-time use reduces children's opportunities to interact and socialize with others, thereby affecting the normal development of healthy social skills [11].

Because technology use interrupts the daily activities of children, it can result in decreased physical activity. Approximately 3.2 million deaths per year globally are related to physical inactivity; it is thus a risk factor for high mortality. Physical activity is essential to stabilize blood pressure and glucose levels, maintain normal body weight, improve sleep patterns, and improve immune response and metabolism [12]. According to the World Health Organization (WHO), the developing child needs at least one hour per day of moderate to vigorous intensity physical activity [12]. The benefit is higher if the daily activity exceeds 60 min [12].

Factors that limit children's physical activity have been previously investigated. Brustad [13] found that children's attraction to physical activity is strongly related to social and psychological variables. Sex, parental socialization, and a child's self-perception characteristics may affect their physical activity behaviors [13]. Maturo \& Cunningham [14] discussed the influence of friendship in promoting lifelong healthy habits in children. Low-income families often have limited financial resources to afford physical activity opportunities for their children and working parents have limited time to interact during physical activity with their children. Figaji and Philips [15] recommend that parents, teachers, and friends should support children's participation in physical activity, especially since they spend a considerable time at school.

Technology use among children is one of the predicting factors for physical inactivity. Kenney and Gortmaker [16] found that excessive use of smartphones, tablets, computers, and videogames was positively related to a lack of physical activity. Moreover, television time was found to be a factor limiting a child's physical activity time [17]. One study conducted on five-year-old children showed that those with high technology use are less active and more likely to have sedentary lifestyles [18]. Recently, Webster et al. [19] showed positive associations between fundamental motor skills and vigorous physical activity among preschoolers, but inverse associations with screen-time.

To our knowledge, studies investigating the relationship between technology use and physical activity among typically-developing children have been conducted in North America [16,19-23], Europe [3,6,17,18,24-29], Australia [4,14,30,31], and in a few countries in Asia [32-34] and Africa [15]. The only study that was conducted in Saudi Arabia was in 2014 and with adolescents aged between 15 and 19 years of age to investigate the association of dietary habits with physical activity and technology use [35]. Therefore, the objectives of this study were to investigate the relationship between technology use and physical activity among typically-developing Saudi children aged between 6-12 years, and to measure the association between sociodemographic characteristics, technology use, and physical activity level.

\section{Materials and Methods}

\subsection{Design}

A cross sectional study was conducted to investigate the relationship between technology use and physical activity level among typically-developing Saudi Arabian children using an online-questionnaire survey. Physical activity is defined as "any bodily movement produced by skeletal muscles that requires energy expenditure" [8]. Participants in the study included parents of 
typically-developing children between the ages of 6-12 years. Participants who identified themselves as parents of typically-developing children between the ages of 6-12 years within Saudi Arabia and who agreed to participate in the study were eligible. This study was approved in advance by the Institutional Review Board (IRB) of Princess Nourah bint Abdulrahman University (17-0197). An anonymous online approach was adopted and a statement in the introduction of the survey clarified that participation was entirely voluntary, participants could withdraw at any time, and privacy and confidentiality of participant information would be completely protected. Participants were recruited via convenience and snowball sampling by word-of-mouth and referral strategies. A calculated sample of 400 parents would provide a margin of error of $5 \%$ from the true values at a $95 \%$ confidence level. Consequently, the total number of the respondents was increased by $14 \%$ to obtain a sample of 458 , accounting for nonresponse.

The datasets used and/or analyzed during the current study are available from the corresponding author on reasonable request.

\subsection{Procedure and Tools}

An anonymized survey was distributed using an online platform to recruit parents of typically-developing Saudi Arabian children. Parents completed the survey on demographics, electronics use and physical activity in the Arabic language. The survey took approximately 8 to $10 \mathrm{~min}$ to be completed by the parents. Incomplete and duplicate questionnaires were discarded.

The survey consisted of three parts: demographic data, Children's Physical Activity Questionnaire (CPAQ) [36] and The Impact of Technology on Children [7].

\subsubsection{Part I: Demographic Data}

A personal information questionnaire prepared by the researchers was used to gather sociodemographic information. It was divided into three parts. The first section covered information related to the parents (relation to the child (mother, father), age, educational level, and marital status). The second section covered information related to the child (age and sex). The third section covered information regarding the family (family monthly income, number of children, district).

\subsubsection{Part II: Children's Physical Activity Questionnaire (CPAQ)}

Parents were required to assess mode, frequency, and duration of physical activity and sedentary activities, including school time and leisure time, over the past seven days. The response options were indicated by "yes" or "no" and by indicating the total time spent on the activity during the week (hours per week). The first section of the questionnaire assessed activities performed during the past seven days, including soccer, volleyball, tennis, swimming, basketball, and running. The second section evaluated leisure time activities including bike riding, household chores, playing with pets, bouncing on the trampoline, scooter, playing on playground equipment, walking, or skipping rope. Total non-school sedentary time was also calculated from the time reported in the questionnaire, and included time for activities such as arts and crafts, homework, listening to music, traveling in the car/bus, reading, and playing board games/cards. Total screen-time was also calculated and included all time spent using computer/internet/devices, watching television/videos, and playing computer games during the day, outside school hours [37]. The validity and reliability of the test have been reported in several studies and, although study designs and populations have been varied, overall results have been convincing. The questionnaire showed high reliability ranging from 0.78 to 0.94 , and moderate validity ranging from 0.63 to 0.71 [38-42].

\subsubsection{Part III: The Impact of Technology on Children}

The Impact of Technology on Children questionnaire [7] was developed by Dr. Jacqui Taylor from Bournemouth University, Psychology Research Centre, Talbot Campus to assess the impact of technology on children. This questionnaire is suitable for use in children aged 4-12. It contains 
questions regarding the child's use of technology, after-school activities, sleep patterns, behavior, and emotions. For the purpose of the current study and to avoid repetition, only the questions related to the child's use of technology were used. This part of the survey included questions about the child's ownership of electronic devices, number and type/s of device/s owned by the child, age when the child first owned a device, number of hours/day spent watching television or DVDs, playing video games such as PS3 ${ }^{\circledR}$ (Sony Corporation, Tokyo, Japan), Xbox ${ }^{\circledR}$ (Microsoft, Redmond, WA, USA), or $\mathrm{Wii}^{\circledR}{ }^{\circledR}$ (Foxconn, New Taipei City, Taiwan) or playing internet games, playing on a portable games console, e.g., iPad ${ }^{\circledR}$ (Foxconn, New Taipei City, Taiwan), iPod ${ }^{\circledR}$ (Apple Inc., Cupertino, CA, USA), PSP $^{\circledR}$ (Sony Corporation, Tokyo, Japan), or Nintendo DS ${ }^{\circledR}$ (Foxconn, New Taipei City, Taiwan), and use of Facebook or other social Networking sites, e.g., Twitter (Twitter Inc., San Francisco, CA, USA) or Instagram (Facebook Inc., Menlo Park, CA, USA).

\subsection{Translation of the Questionnaires}

CPAQ and the Research Questionnaire on the Impact of Technology on Children were translated into Arabic and validated before use, using a standardized forward and backward translation procedure, as recommended by Bradley [43]. Initial translation of the questionnaires from English to Arabic was performed by a panel of three health experts who speak both languages fluently. Another bilingual health professional, blinded to the English version, backward-translated the questionnaires into English. A certified simultaneous Arabic-English interpreter assessed the backward-translated English version of both questionnaires to maintain the semantics and meanings of the English versions. Using the first-translated questionnaires, a pilot test was conducted among 10 participants. For this pilot test, the questionnaires were self-administered. A face-to-face interview was then performed by the researcher to ask the participants whether any items were confusing or difficult to answer. The first-translated questionnaires were then revised accordingly by the two initial translators to develop the final Arabic version, considering the feedback and proposed changes based on the pilot test. The final Arabic version was re-pilot tested among another five participants to confirm that the instructions, questions, and response options could be clearly understood.

\subsection{Data Analysis}

Statistical analysis was performed using IBM SPSS Statistics for Windows, Version 20.0 (IBM Corp., Armonk, NY, USA). Descriptive statistics were used to present the general characteristics of the participants using frequencies and percentages for categorical variables and means and standard deviations for quantitative variables. Pearson correlation and a Mann-Whitney $U$ test were used to assess the relationship between technology use and physical activity level among typically-developing children. A chi-squared test was used to assess the relationship between technology use and sociodemographic variables. Statistical significance was set at $p<0.05$. The analysis of the Research Questionnaire on the Impact of Technology on Children was as follows.

Technology consumption time was dichotomized for statistical purposes using median as a cutoff point as follows: total hours spent on the internet, social media, video games, and portable devices was calculated then subjects were divided into two groups. The first and second groups included children who spent $5 \mathrm{~h}$ or less (screen-time $\leq 5 \mathrm{~h}$ ), the low screen-time users, while those using screens for $6 \mathrm{~h}$ or more (screen-time $\geq 6 \mathrm{~h}$ ) are categorized as high screen-time users.

For the CPAQ, physical activities were classified depending on the metabolic equivalent of task (MET) into three categories: light-intensity (MET < 3), moderate-intensity (MET 3 to 6), and vigorous-intensity (MET $>6$ ). The physical activities' MET values were obtained from the Compendium of Physical Activities; the updated version of activity codes and MET intensities were used [44]. Accordingly, each child's physical activity hours were calculated during the week and divided, based on each MET. The highest number of hours in each category was recorded as the child's activity level. 


\section{Results}

\subsection{Sample Characteristics}

After 52 responses were excluded because of incomplete questionnaires, 458 parents responded to the survey. The results of the demographic characteristics of the study population showed that $86.5 \%$ of responses were from mothers $(n=396)$ and $13.5 \%$ from fathers $(n=62)$. The highest response was from parents aged $30-35$ years $(n=256 ; 55.9 \%)$, followed by those aged $35-40(n=139 ; 30.3 \%), 25-30$ $(n=44 ; 9.6 \%)$, and the lowest from those $>40(n=19 ; 4.1 \%)$.

Most respondents were married $(n=418 ; 91.3 \%)$. Only $3.7 \%$ were divorced $(n=17), 1.5 \%$ separated $(n=7)$, and $3.5 \%$ widowed $(n=16)$. The majority of respondents $(n=317 ; 69.2 \%)$ had a bachelor's degree, while $11.4 \%$ were high school graduates $(n=52), 17.2 \%$ were postgraduates $(n=79), 1.7 \%$ had less than high school degree $(n=8)$, and only $2(0.4 \%)$ were not educated.

The monthly income of most respondents ranged from 10,000 to 15,000 SAR $(\$ 2600-\$ 4000)(n=151$; $33 \%)$, followed by those who earned more than 20,000 SAR $(\$ 5000)(n=124 ; 27.1 \%)$, those earning between 15,000-20,000 SAR (\$4000-\$5000) $(n=87 ; 19 \%)$, from 5000-10000 SAR (\$1300-\$2600) $(n=74 ;$ $16.2 \%)$, and less than 5000 SAR $(\$ 2600)(n=22 ; 4.6 \%)$. The children of parents from whom the data were collected were aged between $6-12$ years (mean age; $8.44 \pm 2.07$ years), consisting of more boys $(n=244 ; 53.3 \%)$ than girls $(n=214 ; 46.7 \%)$.

\subsection{Technology Use Results}

Table 1 shows a statistically significant association between screen-time use in children and marital status, family income, child's age, and child's ownership of device $(p<0.05)$. Conversely, there was no significant association between screen-time use and educational level, parental age, sex of the child, and the child's age when he/she owned their first device.

Table 1. Association between technology use and demographic data.

\begin{tabular}{|c|c|c|c|c|}
\hline \multirow{2}{*}{ Variables } & \multirow{2}{*}{$\begin{array}{l}\text { Screen-Time } \leq 5 \mathrm{~h} \\
n(\%) 258(56.33 \%)\end{array}$} & \multirow{2}{*}{$\begin{array}{l}\text { Screen-Time } \geq 6 \mathrm{~h} \\
n(\%) 200(43.67 \%)\end{array}$} & \multicolumn{2}{|c|}{ Used Test } \\
\hline & & & $p$-Value & Value \\
\hline \multicolumn{5}{|c|}{ Marital status ** } \\
\hline Married & $239(92.6)$ & $179(89.5)$ & $0.05 *$ & 12.69 \\
\hline Widowed & $12(4.7)$ & $4(2.0)$ & & \\
\hline Divorced & $3(1.2)$ & $14(7.0)$ & & \\
\hline Separated & $4(1.6)$ & $3(1.5)$ & & \\
\hline \multicolumn{5}{|c|}{ Educational level ** } \\
\hline Not educated & $1(0.4)$ & $1(0.5)$ & & \\
\hline Under high school & $1(0.4)$ & $7(3.5)$ & 0.074 & 17.56 \\
\hline High school & $21(8.1)$ & $31(15.5)$ & & \\
\hline Bachelor & $196(76.0)$ & $121(60.5)$ & & \\
\hline Postgraduate & $39(15.1)$ & $40(40.0)$ & & \\
\hline \multicolumn{5}{|c|}{ Age group of parents (years) } \\
\hline $25-30$ & $27(10.5)$ & $17(8.5)$ & & \\
\hline $30-35$ & $145(56.2)$ & $111(55.0)$ & 0.34 & 3.34 \\
\hline $35-40$ & $79(30.6)$ & $60(30.0)$ & & \\
\hline More than 40 & $7(2.7)$ & $12(6.0)$ & & \\
\hline \multicolumn{5}{|l|}{ Income (SAR) } \\
\hline Less than 5000 & $20(7.8)$ & $2(1.0)$ & 0.001 * & 18.3 \\
\hline 5000-10,000 & $34(13.2)$ & $40(20.0)$ & & \\
\hline $10,000-15,000$ & $78(30.2)$ & $73(36.5)$ & & \\
\hline $15,000-20,000$ & $57(22.1)$ & $30(15.0)$ & & \\
\hline More than 20,000 & $69(26.7)$ & $55(27.5)$ & & \\
\hline
\end{tabular}


Table 1. Cont.

\begin{tabular}{|c|c|c|c|c|}
\hline & \multirow{2}{*}{$\begin{array}{l}\text { Screen-Time } \leq 5 \mathrm{~h} \\
n(\%) 258(56.33 \%)\end{array}$} & \multirow{2}{*}{$\begin{array}{l}\text { Screen-Time } \geq 6 \mathrm{~h} \\
n(\%) 200(43.67 \%)\end{array}$} & \multicolumn{2}{|c|}{ Used Test } \\
\hline & & & $p$-Value & Value \\
\hline \multicolumn{5}{|c|}{ Sex (of child) } \\
\hline Male & $136(52.7)$ & $108(54.0)$ & & \\
\hline Female & $122(47.3)$ & $92(46.0)$ & 0.78 & 0.075 \\
\hline \multicolumn{5}{|c|}{ Child's age (years) } \\
\hline 6 & $85(32.9)$ & $42(21.0)$ & $0.000 *$ & 20.19 \\
\hline 7 & $29(11.2)$ & $14(7.0)$ & & \\
\hline 8 & $51(19.8)$ & $42(21.0)$ & & \\
\hline 9 & $19(7.4)$ & $18(9.0)$ & & \\
\hline 10 & $38(14.7)$ & $31(15.5)$ & & \\
\hline 11 & $17(6.6)$ & $16(8.0)$ & & \\
\hline 12 & $19(7.4)$ & $37(18.5)$ & & \\
\hline \multicolumn{5}{|c|}{ Does the child have his/her own device? } \\
\hline Yes & $190(73.6)$ & $186(93.0)$ & $0.000 *$ & 28.71 \\
\hline No & $68(26.4)$ & $14(7.0)$ & & \\
\hline \multicolumn{5}{|c|}{ Child's age when owned device ${ }^{* *}$} \\
\hline 1 & $1(0.4)$ & $0(0.0)$ & & \\
\hline 2 & 4 (1.6) & $6(3.0)$ & 0.75 & 24.92 \\
\hline 3 & $17(6.6)$ & $21(10.5)$ & & \\
\hline 4 & $62(24.0)$ & $34(17.0)$ & & \\
\hline 5 & 45 (17.4) & $24(12.0)$ & & \\
\hline 6 & 48 (18.6) & $44(22.0)$ & & \\
\hline 7 & $22(8.5)$ & 25 (12.5) & & \\
\hline 8 & 33 (12.8) & $41(20.5)$ & & \\
\hline 9 & $11(4.3)$ & $2(1.0)$ & & \\
\hline 10 & 4 (1.6) & $1(0.5)$ & & \\
\hline
\end{tabular}

${ }^{*}$ Note: $p$-value, statistically significant at $\leq 0.05 ; \%=$ percentage. ${ }^{* *}$ Fisher's exact test was used-Otherwise a chi-squared test was used. Abbreviation: $n=$ number of participants.

\subsection{Physical Activity and Technology Use Results}

Table 2 shows a significantly negative correlation between hours of technology use (television, social media, video games, internet, and portable devices) and a high level of physical activity $(r=-0.138$; $p=0.047)$. Conversely, there was weak negative correlation between technology use and moderate physical activity; however, it was not significant $(r=-0.130 ; p=0.062)$. There was a positively weak, insignificant correlation between technology use and low physical activity $(r=0.136 ; p=0.051)$.

Table 2. Correlation between screen-time use and level of physical activity.

\begin{tabular}{clcccc}
\hline \multirow{2}{*}{ Correlation } & Screen Time & High Level & Moderate Level & Low Level \\
\hline \multirow{2}{*}{ Screen-time } & Pearson Correlation & 1 & $-0.138^{*}$ & -0.130 & 0.136 \\
\cline { 2 - 6 } & Sig. (2-tailed) & & 0.047 & 0.062 & 0.051 \\
\hline \multirow{2}{*}{ High level } & Pearson Correlation & $-0.138^{*}$ & 1 & $0.458^{* *}$ & $0.298^{* *}$ \\
\cline { 2 - 6 } & Sig. (2-tailed) & 0.047 & & 0.000 & 0.000 \\
\hline \multirow{2}{*}{ Moderate level } & Pearson Correlation & -0.130 & $0.458^{* *}$ & 1 & $0.377^{* *}$ \\
\cline { 2 - 6 } & Sig. (2-tailed) & 0.062 & 0.000 & & 0.000 \\
\hline \multirow{2}{*}{ Low level } & Pearson Correlation & 0.136 & $0.298^{* *}$ & $0.377^{* *}$ & 1 \\
\cline { 2 - 6 } & Sig. (2-tailed) & 0.051 & 0.000 & 0.000 & \\
\hline
\end{tabular}

\footnotetext{
${ }^{*}$ Correlation is significant at the 0.05 level (2-tailed). ${ }^{* *}$ Correlation is significant at the 0.01 level (2-tailed).
} 
Regression analysis revealed that age of the child, educational level of the parents, screen time use, and owning electrical devices significantly predicted the practice level of physical activity among children of sampled parents $(p<0.05)$ (Table 3$)$.

Table 3. Predictors of low level physical activity level among children of sampled participants.

\begin{tabular}{|c|c|c|c|c|c|c|}
\hline \multirow{2}{*}{ Variable } & \multirow{2}{*}{$\ddagger \mathbf{B}$} & \multirow{2}{*}{$* * \mathrm{SE}$} & \multirow{2}{*}{${ }^{\wedge} \mathbf{B}$} & \multirow{2}{*}{${ }^{\wedge} p$ Value } & \multicolumn{2}{|c|}{$95.0 \%$ Confidence Interval for $B$} \\
\hline & & & & & Lower Bound & Upper Bound \\
\hline Gender of the child & -0.226 & 0.211 & 0.798 & 0.284 & 0.528 & 1.206 \\
\hline $\begin{array}{l}\text { Age group of the } \\
\text { parents }\end{array}$ & -0.188 & 0.233 & 0.829 & 0.419 & 0.525 & 1.308 \\
\hline Marital status & -0.563 & 0.354 & 0.570 & 0.111 & 0.285 & 1.139 \\
\hline Educational level & -1.827 & 0.881 & 0.161 & $0.038^{\wedge}$ & 0.029 & 0.904 \\
\hline Family income & -0.234 & 0.247 & 0.791 & 0.343 & 0.488 & 1.284 \\
\hline Screen time use & -0.525 & 0.204 & 0.592 & $0.010^{\wedge}$ & 0.396 & 0.883 \\
\hline Own electronic device & 0.009 & 0.270 & 0.250 & $0.000^{\wedge}$ & 0.132 & 0.472 \\
\hline $\begin{array}{l}\text { Child age when owned } \\
\text { device }\end{array}$ & 0.430 & 0.227 & 1.537 & $0.041^{\varkappa}$ & 1.984 & 2.401 \\
\hline
\end{tabular}

\section{Discussion}

\subsection{Correlation Between Technology Use and Physical Activity}

The present study found that hours of technology use including television, social media, video games, internet, and portable devices had a significantly negative correlation with a high level of physical activity. Our findings are consistent with those of previous studies; Serrano-Sanchez et al. [29] and Motamed-Gorji et al. [45] found that the more screen-time spent, the less physical activity the child performs. Rideout et al. [46] suggested that youths can spend up to $11 \mathrm{~h}$ per day using screen-based technologies, which can be associated with snacking and excessive eating, potentially replacing participation in physical activities [47]. Al-Hazzaa et al. [35] conducted a similar study to that of Rideout et al. [46] on Saudi adolescents aged between 15 and 19 years of age to investigate the association of dietary habits with PA and technology use. Al-Hazzaa et al. [35] reported that excessive screen-time use was associated with significantly higher consumption of unhealthy food and inactivity.

The current study also showed that children who spend $\leq 5 \mathrm{~h}$ on their technology devices had a higher level of physical activity, and those who spend $\geq 6 \mathrm{~h}$ tend to have a lower level of physical activity. In contrast to our study, one study found that spending more than $2 \mathrm{~h}$ daily on screen-time had no association with lower levels of physical activity [26]. Karaca, et al. [32] examined the screen-time of adolescents by gender, school type, and sport participation using the household activities and sport indexes of the Physical Activity Assessment Questionnaire. They found that screen-time does not affect participation in physical activity. However, gender and school type (public or private) had a direct effect, as male students and those attending private schools had a higher rate of screen time than their counterparts [32]. Their results were linked to the customs and traditions of the country and to the socioeconomic class of the students. Females are more engaged with household work than males, and students of a high socioeconomic class have more access to technology at home than students with of a low socioeconomic class [32]. There has been no study until now that has compared the effect of technology use on PA between students in public and private Saudi schools. However, one can expect it to be high in students in private schools, and that can be attributed not only to the socioeconomic class of the students, but also to the schools' financial resources. Private schools in Saudi Arabia are 
generally more technologically advanced than public schools, which might contribute to reduction in PA level of students in the latter.

Previous studies have shown that technology use is associated with a sedentary lifestyle, which can lead to several risk factors, the most prominent being obesity $[48,49]$. These studies found a significant relationship between increased body mass index (BMI)/obesity and sedentary behaviors such as watching television, computer use, and video games [20,50,51]. High screen use was recently found to be significantly associated with lower physical fitness [52]. Children exceeding screen time recommendations (at least 60 min of moderate to vigorous PA per day [53]) are at $60 \%$ high risk of having poor or very poor fitness level [52]. Tremblay et al. [54] found an inverse relationship between high sedentary behavior time and lower cardiorespiratory fitness, musculoskeletal fitness, and maximal oxygen uptake $\left(\mathrm{VO}_{2 \max }\right)$. Furthermore, Pardee et al. [55], found that the chances of having metabolic syndrome in children with $\geq 5 \mathrm{~h}$ /day of screen-time were three times higher than in those with $\leq 1 \mathrm{~h} /$ day. Children with $4 \mathrm{~h} /$ day of screen-time were 3.3 times more likely to have hypertension than their counterparts with $<2 \mathrm{~h} /$ day.

Participating in outdoor physical activity is one of the most important elements of an active lifestyle [56]. However, in Saudi Arabia, there are many factors that could limit participation in physical activity, such as customs and traditions, lack of local facilities, security, and road traffic density [57-59]. All these and other factors can be investigated in future studies.

\subsection{Association between Socio-Demographics and Technology Use}

The association between socio-demographics and technology time consumption among children was tested in the present study. No significant association between parental age and children's use of technology use was found; however, mixed results have been reported previously. Some studies revealed that children of younger parents are more prone to using technology $[25,60]$. Other studies found no association between parental age and the child's technology use $[22,24,61]$. The current study also showed no significant association between parental educational level or marital status and technology use. However, Carson and Janssen [20] found a negative association between parental educational level and use of technology, as higher technology use was found among children of parents with lower educational levels [62]. Furthermore, there was a significant correlation between marital status and technology use. A few studies have reported that children living with a single parent are more likely to use technology compared to children living in families with both parents $[30,63,64]$.

This present study showed that family monthly income had an effect on the child's technology use, similar to the findings of other studies [21,65]. Some studies have reported a positive association between family monthly income and child's technology use, indicating that children of high-income families use technology more than those of low-income families, due to the reported ownership of devices [21,65]. On the other hand, other studies reported no association [33,61], or a negative association between family income and the child's use of technology [60]. Several studies have investigated the relationship between ownership of devices and screen time consumption among children $[22,31,62,66,67]$. For instance, Alturki et al. [68] conducted a multicenter, cross-sectional study in Riyadh, Saudi Arabia on 1023 children between 9-12 years of age to investigate the relationship between ownership and duration spent on various electronic screen devices and association with the child's weight status [68].They found a significant relation between device ownership and screen time, which was positively associated with the occurrence of obesity [68]. These studies are consistent with the current findings, as children who own their devices were prone to spend more time using technology. This result could be explained by the fact that ownership of a device leads to easy access to games, programs, and applications [22].

In contrast to the current study, significant differences between boys and girls have been observed in some studies regarding technology use. Some studies showed that girls spend more time watching television than boys [25,27]. Al-Hazzaa et al. [35] reported that technology use was significantly higher among Saudi female students than their counterparts; additionally, they were significantly less active 
and more sedentary. On the other hand, one study conducted in the USA [69] revealed that boys spend more time using technology than girls. Pyper et al. [70] and Dolatabadi et al. [71] found significantly more time spent in video game playing and computer/laptop use among boys than girls. In the Middle East, the tendency of boys to use technology more than girls might be attributed to culture and tradition, as the female role in the family revolves generally around doing household chores and helping family members. This could also be related to the skills required for using technology and different perspective regarding technology use between genders [71].

This study found a significant relationship between technology consumption time and the child's age. Other studies found that older children are more likely to spend more time using technology than younger children $[21,60,72]$. This association may be attributed to the fact that older children are more skilled in using technology and able to access different types of technology [20]. However, Roberts et al. [73] reported that, on average, children aged between 8-10, 10-14, and 15-18 years spend 65, 52, and $33 \mathrm{~min}$, respectively, on computer games per day. Roberts et al. attributed the increase in time spent on computer games to rapid advancements in communication and entertainment technologies and the growing use of handheld devices for game playing [73].

\section{Conclusions}

In conclusion, this study showed that high use of technology was significantly associated with low level of activity. Children who spend $<5 \mathrm{~h}$ each week on their devices tend to have higher levels of physical activity compared to those who spend $>6 \mathrm{~h}$. Ownership of a device was significantly associated with higher technology time consumption. Furthermore, age of the child, educational level of the parents, screen time use, and owning electrical devices significantly predicted the level of physical activity among children of sampled parents. Thus, parental involvement is needed to reduce the time spent on screens, which can have a high impact on a child's physical activity level.

\subsection{Implications and Recommendations}

Since children spend most of their time at school, the Ministry of Education should provide various sports and activity classes that enable children to participate in physical activity based on their preferred sports. The Ministry of Education should also work on improving the outdoor areas of schools, as some are poorly equipped and not designed for sports activities. Well-organized partnerships should be established between the Ministry of Education, Ministry of Health, Ministry of Municipalities, and private investors to design and invest in more appropriate places for children to practice their sports and to support the promotion of physical activity among children. Collaboration between the Ministry of Health and the Ministry of Information is recommended to educate families about the side effects of technology overuse. Furthermore, software developers need to be supported to design more active video games. Parents should be educated about the side effects of overuse of technology and encouraged to apply their role in controlling and limiting a child's screen time and access to the internet. Parents are advised to increase outdoor activities and promote participation in housework.

\subsection{Limitations}

The used online questionnaire is a parent-reported questionnaire; therefore, we might have unintentionally missed parents with low literacy level, low technical abilities, with busy schedules, or who did not have access to computers or the Internet. Some of the questionnaire components were too long and resulted in incomplete answers, which were excluded later.

\subsection{Future Research}

Our study was limited to the central region of Saudi Arabia. Due to variation in sociodemographic variables between regions in KSA, future studies should be conducted to assess the relationship between physical activities and sociodemographic data and technology use between regions. The opinions of 
children on their abilities in the activities they engage in needs further investigation. Furthermore, using objective tools to measure the effect of technology use on physical activity rather than relying on self-reported data might help in developing more effective and cost-effective interventions.

\subsection{Key Messages}

- Daily technology use of devices by children is rising.

- Daily technology use of devices by children might lead to an inadequate level of physical activity.

- Children who spend $<5 \mathrm{~h}$ each week on their devices tend to have higher levels of physical activity compared to those who spend $>6 \mathrm{~h}$.

- Parental involvement is needed to reduce the time children spend on screens, which can have a high impact on a child's physical activity level.

- Inadequate physical activity among children may be influenced by the educational level of the parents.

Author Contributions: Conceptualization T.A. and R.A. (Rifan Almuhanna); methodology, J.A.; software, E.A.; validation, E.A., E.M. and R.A. (Reem Alwhaibi); formal analysis, T.A., R.A. (Rifan Almuhanna) and E.M.; investigation, E.M.; resources, J.A.; data curation, R.A. (Rifan Almuhanna) and E.A.; writing-original draft preparation, T.A., R.A. (Rifan Almuhanna), J.A. and E.A.; writing-review and editing, E.M. and R.A. (Reem Alwhaibi); visualization, R.A. (Reem Alwhaibi); supervision, R.A. (Reem Alwhaibi); project administration, R.A. (Reem Alwhaibi); funding acquisition, R.A (Reem Alwhaibi). All authors have read and agreed to the published version of the manuscript.

Funding: This research received no external funding.

Acknowledgments: We would like to express our thanks to those who translated the tools used in our study, to those who helped us with data analyses, to those who helped edit our manuscript, and to all of the participants who gave their time to complete the study questionnaire. The manuscript has not been published and will not be submitted elsewhere for publication while being considered by the journal Disability Health Journal. There is no prior presentation of abstracts at meetings and posting any part or all of the content on a website, even in draft form, including a "preprint" site.

Conflicts of Interest: The authors declare no conflict of interest.

\section{References}

1. Radesky, J.; Schumacher, J.; Zuckerman, B. Mobile and Interactive Media Use by Young Children: The Good, the Bad, and the Unknown. Pediatrics 2015, 135, 1-3. [CrossRef] [PubMed]

2. General Authority for Statistics. Demography Survay 2016. Available online: https://www.stats.gov.sa/en (accessed on 19 November 2017).

3. Engberg, E.; Figueiredo, R.A.O.; Rounge, T.B.; Weiderpass, E.; Viljakainen, H. Heavy screen users are the heaviest among 10,000 children. Sci. Rep. 2019, 9, 11158. [CrossRef] [PubMed]

4. Dunstan, D.W.; Barr, E.L.M.; Shaw, J.E.; Magliano, D.J.; Zimmet, P.; Salmon, J.; Cameron, A.J.; Owen, N.; Healy, G.N.; Balkau, B. Response to Letters Regarding Article, "Television Viewing Time and Mortality: The Australian Diabetes, Obesity and Lifestyle Study (AusDiab).". Circulation 2010, 121, 384-391. [CrossRef] [PubMed]

5. Page, A.S.; Cooper, A.R.; Griew, P.; Jago, R. Children's Screen Viewing is Related to Psychological Difficulties Irrespective of Physical Activity. Pediatrics 2010, 126, e1011-e1017. [CrossRef]

6. Braig, S.; Genuneit, J.; Walter, V.; Brandt, S.; Wabitsch, M.; Goldbeck, L.; Brenner, H.; Rothenbacher, D. Screen Time, Physical Activity and Self-Esteem in Children: The Ulm Birth Cohort Study. Int. J. Environ. Res. Public Health 2018, 15, 1275. [CrossRef]

7. Mesman, G.R.; Kuo, D.Z.; Carroll, J.L.; Ward, W.L. The Impact of Technology Dependence on Children and Their Families. J. Pediatr. Health Care 2013, 27, 451-459. [CrossRef]

8. World Health Organization. Global Strategy on Diet, Physical Activity and Health. 2019. Available online: https://www.who.int/dietphysicalactivity/pa/en/ (accessed on 18 August 2019).

9. Oswald, T.K.; Rumbold, A.R.; Kedzior, S.G.E.; Moore, V.M. Psychological impacts of "screen time" and "green time" for children and adolescents: A systematic scoping review. PLoS ONE 2020, 15, e0237725. [CrossRef] 
10. Mundy, L.K.; Canterford, L.; Hoq, M.; Olds, T.; Moreno-Betancur, M.; Sawyer, S.; Kosola, S.; Patton, G.C. Electronic media use and academic performance in late childhood: A longitudinal study. PLoS ONE 2020, 15, e0237908. [CrossRef]

11. Hinkley, T.; Brown, H.; Carson, V.; Teychenne, M. Cross sectional associations of screen time and outdoor play with social skills in preschool children. PLoS ONE 2018, 13, e0193700. [CrossRef]

12. World Health Organization. Physical Activity. Available online: http://www.who.int/topics/physical_activity/ en/ (accessed on 17 October 2017).

13. Brustad, R.J. Who Will Go Out and Play? Parental and Psychological Influences on Children's Attraction to Physical Activity. Pediatr. Exerc. Sci. 1993, 5, 210-223. [CrossRef]

14. Maitland, C.; Stratton, G.; Foster, S.; Braham, R.; Rosenberg, M.S. A place for play? The influence of the home physical environment on children's physical activity and sedentary behaviour. Int. J. Behav. Nutr. Phys. Act. 2013, 10, 99. [CrossRef] [PubMed]

15. Figaji, T.; Phillips, J. factors influencing physical activity participation among school going children. J. Clin. Health Sci. 2010, 5, 34-40.

16. Kenney, E.L.; Gortmaker, S.L. United States Adolescents' Television, Computer, Videogame, Smartphone, and Tablet Use: Associations with Sugary Drinks, Sleep, Physical Activity, and Obesity. J. Pediatr. 2017, 182, 144-149. [CrossRef] [PubMed]

17. McDougall, J.; Duncan, M.J. Children, video games and physical activity: An exploratory study. Int. J. Disabil. Hum. Dev. 2008, 7, 89-94. [CrossRef]

18. Nilsson, A.; Andersen, L.B.; Ommundsen, Y.; Froberg, K.; Sardinha, L.; Piehl-Aulin, K.; Ekelund, U. Correlates of objectively assessed physical activity and sedentary time in children: A cross-sectional study (The European Youth Heart Study). BMC Public Health 2009, 9, 322. [CrossRef]

19. Webster, E.K.; Martin, C.K.; Staiano, A.E. Fundamental motor skills, screen-time, and physical activity in preschoolers. J. Sport Health Sci. 2019, 8, 114-121. [CrossRef]

20. Carson, V.; Janssen, I. Associations between factors within the home setting and screen time among children aged 0-5 years: A cross-sectional study. BMC Public Health 2012, 12, 539. [CrossRef]

21. Carson, V.; Kuzik, N. Demographic correlates of screen time and objectively measured sedentary time and physical activity among toddlers: A cross-sectional study. BMC Public Health 2017, 17, 187. [CrossRef]

22. Connell, S.L.; Lauricella, A.R.; Wartella, E. Parental Co-Use of Media Technology with their Young Children in the USA. J. Child. Media 2015, 9, 5-21. [CrossRef]

23. Tremblay, M.S.; Leblanc, A.G.; Janssen, I.; Kho, M.E.; Hicks, A.; Murumets, K.; Colley, R.C.; Duggan, M. Canadian Sedentary Behaviour Guidelines for Children and Youth. Appl. Physiol. Nutr. Metab. 2011, 36, 59-64. [CrossRef]

24. Asplund, K.M.; Kair, L.R.; Arain, Y.H.; Cervantes, M.; Oreskovic, N.M.; Zuckerman, K.E. Early Childhood Screen Time and Parental Attitudes Toward Child Television Viewing in a Low-Income Latino Population Attending the Special Supplemental Nutrition Program for Women, Infants, and Children. Child. Obes. 2015, 11, 590-599. [CrossRef] [PubMed]

25. Cillero, I.H.; Jago, R. Sociodemographic and home environment predictors of screen viewing among Spanish school children. J. Public Health 2011, 33, 392-402. [CrossRef] [PubMed]

26. Melkevik, O.; Torsheim, T.; Iannotti, R.J.; Wold, B. Is spending time in screen-based sedentary behaviors associated with less physical activity: A cross national investigation. Int. J. Behav. Nutr. Phys. Act. 2010, 7, 46. [CrossRef] [PubMed]

27. O'Brien, W.; Issartel, J.; Belton, S. Relationship between Physical Activity, Screen Time and Weight Status among Young Adolescents. Sports 2018, 6, 57. [CrossRef] [PubMed]

28. Peiró-Velert, C.; Valencia-Peris, A.; González, L.M.; García-Massó, X.; Serra-Añó, P.; Devís-Devís, J. Screen Media Usage, Sleep Time and Academic Performance in Adolescents: Clustering a Self-Organizing Maps Analysis. PLoS ONE 2014, 9, e99478. [CrossRef] [PubMed]

29. Serrano-Sanchez, J.A.; Martí-Trujillo, S.; Lera-Navarro, A.; Dorado-García, C.; González-Henríquez, J.J.; Sanchís-Moysi, J. Associations between Screen Time and Physical Activity among Spanish Adolescents. PLOS ONE 2011, 6, e24453. [CrossRef]

30. Bagley, S.; Salmon, J.; Crawford, D. Family Structure and Children's Television Viewing and Physical Activity. Med. Sci. Sports Exerc. 2006, 38, 910-918. [CrossRef] 
31. Dumuid, D.; Olds, T.; Lewis, L.K.; Maher, C. Does home equipment contribute to socioeconomic gradients in Australian children's physical activity, sedentary time and screen time? BMC Public Health 2016, 16, 736. [CrossRef]

32. Karaca, A.; Çağlar, E.; Bilgili, N.; Ayaz, S. Screen time of adolescents in an economically developing country: The case of Turkey. Ann. Hum. Biol. 2011, 38, 28-33. [CrossRef]

33. Lee, S.T.; Wong, J.E.; Ong, W.W.; Ismail, M.N.; Deurenberg, P.; Poh, B.K. Physical Activity Pattern of Malaysian Preschoolers: Environment, Barriers, and Motivators for Active Play. Asia Pac. J. Public Health 2016, 28 (Suppl. S5), 21S-34S. [CrossRef]

34. Zamani, E.; Chashmi, M.; Hedayati, N. Effect of Addiction to Computer Games on Physical and Mental Health of Female and Male Students of Guidance School in City of Isfahan. Addict. Health 2009, 1, 98-104. [PubMed]

35. Al-Hazzaa, H.M.; Al-Sobayel, H.I.; Abahussain, N.A.; Qahwaji, D.M.; Alahmadi, M.A.; Musaiger, A.O. Association of dietary habits with levels of physical activity and screen time among adolescents living in Saudi Arabia. J. Hum. Nutr. Diet. 2014, 27 (Suppl. S2), 204-213. [CrossRef] [PubMed]

36. Crocker, P.R.; Bailey, D.A.; Faulkner, R.A.; Kowalski, K.C.; McGrath, R. Measuring general levels of physical activity: Preliminary evidence for the Physical Activity Questionnaire for Older Children. Med. Sci. Sports Exerc. 1997, 29, 1344-1349. [CrossRef] [PubMed]

37. Corder, K.; Van Sluijs, E.; Wright, A.; Whincup, P.H.; Wareham, N.J.; Ekelund, U. Is it possible to assess free-living physical activity and energy expenditure in young people by self-report? Am. J. Clin. Nutr. 2009, 89, 862-870. [CrossRef]

38. Aggio, D.; Fairclough, S.J.; Knowles, Z.R.; Graves, L.E.F. Validity and reliability of a modified english version of the physical activity questionnaire for adolescents. Arch. Public Health 2016, 74, 3. [CrossRef]

39. Janz, K.F.; Lutuchy, E.M.; Wenthe, P.; Levy, S.M. Measuring Activity in Children and Adolescents Using Self-Report. Med. Sci. Sports Exerc. 2008, 40, 767-772. [CrossRef]

40. Thomas, E.L.; Upton, D. Psychometric properties of the physical activity questionnaire for older children (PAQ-C) in the UK. Psychol. Sport Exerc. 2014, 15, 280-287. [CrossRef]

41. Gobbi, E.; Elliot, C.; Varnier, M.; Carraro, A. Psychometric Properties of the Physical Activity Questionnaire for Older Children in Italy: Testing the Validity among a General and Clinical Pediatric Population. PLoS ONE 2016, 11, e0156354. [CrossRef]

42. Wang, J.-J.; Baranowski, T.; Lau, W.P.; Chen, T.-A.; Pitkethly, A.J. Validation of the Physical Activity Questionnaire for Older Children (PAQ-C) among Chinese Children. Biomed. Environ. Sci. 2016, 29, 177-186.

43. Bradley, C. Translation of questionnaires for use in different languages and cultures. In Handbook of Psychology and Diabetes: A Guide to Psychological Measurement in Diabetes Research and Practice; Harwood Academic Publishers: Chur, Switzerland, 1994.

44. Ainsworth, B.E.; Haskell, W.L.; Whitt, M.C.; Irwin, M.L.; Swartz, A.M.; Strath, S.J.; O’Brien, W.L.; Bassett, D.R.; Schmitz, K.H.; Emplaincourt, P.O.; et al. Compendium of Physical Activities: An update of activity codes and MET intensities. Med. Sci. Sports Exerc. 2000, 32 (Suppl. S9), S498-S516. [CrossRef]

45. Motamed-Gorji, N.; Qorbani, M.; Nikkho, F.; Asadi, M.; Motlagh, M.E.; Safari, O.; Arefirad, T.; Asayesh, H.; Mohammadi, R.; Mansourian, M.; et al. Association of screen time and physical activity with health-related quality of life in Iranian children and adolescents. Health Qual. Life Outcomes 2019, 17, 2. [CrossRef] [PubMed]

46. Rideout, V.J.; Foehr, U.G.; Roberts, D.F. Generation $M^{2}$ : Media in the Lives of 8-to 18-Year-Olds; Henry J. Kaiser Family Foundation: Menlo Park, CA, USA, 2010.

47. Bulck, J.V.D.; Van Mierlo, J. Energy intake associated with television viewing in adolescents, a cross sectional study. Appetite 2004, 43, 181-184. [CrossRef] [PubMed]

48. Ghobadi, S.; Hassanzadeh-Rostami, Z.; Salehi-Marzijarani, M.; Bellissimo, N.; Brett, N.R.; De Zepetnek, J.O.T.; Faghih, S. Association of eating while television viewing and overweight/obesity among children and adolescents: A systematic review and meta-analysis of observational studies. Obes. Rev. 2018, 19, 313-320. [CrossRef] [PubMed]

49. Hu, E.Y.; Ramachandran, S.; Bhattacharya, K.; Nunna, S. Obesity Among High School Students in the United States: Risk Factors and Their Population Attributable Fraction. Prev. Chronic Dis. 2018, 15, 137. [CrossRef]

50. Marshall, S.J.; Biddle, S.J.H.; Gorely, T.; Cameron, N.; Murdey, I. Relationships between media use, body fatness and physical activity in children and youth: A meta-analysis. Int. J. Obes. 2004, 28, 1238-1246. [CrossRef] 
51. Oliver, C.S. A Review of the Relationship between Screen Time and Low Levels of Physical Activity with Obesity and Sedentary Behaviors in Children and Adolescents. Master's Thesis, Georgia State University, Atlanta, GA, USA, 2017

52. Greier, K.; Drenowatz, C.; Ruedl, G.; Riechelmann, H. Association between daily TV time and physical fitness in 6- to 14-year-old Austrian youth. Transl. Pediatr. 2019, 8, 371-377. [CrossRef]

53. World Health Organization. Health Organization. Health Behavior in School-aged children (HBSC) Study. In International Report from the 2013/2014 Survey; WHO Regional Office for Europe: Copenhagen, Denmark, 2016.

54. Tremblay, M.S.; Leblanc, A.G.; Kho, M.E.; Saunders, T.J.; Larouche, R.; Colley, R.C.; Goldfield, G.S.; Gorber, S.C. Systematic review of sedentary behaviour and health indicators in school-aged children and youth. Int. J. Behav. Nutr. Phys. Act. 2011, 8, 98. [CrossRef]

55. Pardee, P.E.; Norman, G.J.; Lustig, R.H.; Preud'Homme, D.; Schwimmer, J.B. Television Viewing and Hypertension in Obese Children. Am. J. Prev. Med. 2007, 33, 439-443. [CrossRef]

56. Biddle, S.J.; Atkin, A.J.; Cavill, N.; Foster, C. Correlates of physical activity in youth: A review of quantitative systematic reviews. Int. Rev. Sport Exerc. Psychol. 2011, 4, 25-49. [CrossRef]

57. Al-Otaibi, H.H. Measuring Stages of Change, Perceived Barriers and Self efficacy for Physical Activity in Saudi Arabia. Asian Pac. J. Cancer Prev. 2013, 14, 1009-1016. [CrossRef]

58. Alsubaie, A.S.R.; Omer, E.O.M. Physical Activity Behavior Predictors, Reasons and Barriers among Male Adolescents in Riyadh, Saudi Arabia: Evidence for Obesogenic Environment. Int. J. Health Sci. 2015, 9, 400-408. [CrossRef]

59. Awadalla, N.; AboElyazed, A.; Hassanein, M.; Khalil, S.; Aftab, R.; Gaballa, I.; Mahfouz, A. Assessment of physical inactivity and perceived barriers to physical activity among health college students, south-western Saudi Arabia. East. Mediterr. Health J. 2014, 20, 596-604. [CrossRef] [PubMed]

60. Wu, C.S.T.; Fowler, C.; Lam, W.; Wong, H.T.; Wong, C.H.M.; Loke, A.Y. Parenting approaches and digital technology use of preschool age children in a Chinese community. Ital. J. Pediatr. 2014, 40, 44. [CrossRef] [PubMed]

61. Pempek, T.A.; McDaniel, B.T. Young Children's Tablet Use and Associations with Maternal Well-Being. J. Child Fam. Stud. 2016, 25, 2636-2647. [CrossRef]

62. Kılıç, A.O.; Sari, E.; Yucel, H.; Oğuz, M.M.; Polat, E.; Acoglu, E.A.; Senel, S. Exposure to and use of mobile devices in children aged 1-60 months. Eur. J. Nucl. Med. Mol. Imaging 2019, 178, 221-227. [CrossRef]

63. Gorely, T.; Marshall, S.J.; Biddle, S.J.H. Couch kids: Correlates of television viewing among youth. Int. J. Behav. Med. 2004, 11, 152-163. [CrossRef]

64. Colwell, J.; Kato, M. Video game play in British and Japanese adolescents. Simul. Gaming 2005, 36, 518-530. [CrossRef]

65. Nikken, P.; Schols, M. How and Why Parents Guide the Media Use of Young Children. J. Child Fam. Stud. 2015, 24, 3423-3435. [CrossRef]

66. Brindova, D.; Pavelka, J.; Ševčikova, A.; Žežula, I.; Geckova, A.M.; Reijneveld, S.A.; Gecková, A.M. How parents can affect excessive spending of time on screen-based activities. BMC Public Health 2014, 14, 1261. [CrossRef]

67. Radesky, J.S.; Weeks, H.M.; Ball, R.; Schaller, A.; Yeo, S.; Durnez, J.; Tamayo-Rios, M.; Epstein, M.; Kirkorian, H.; Coyne, S.; et al. Young Children's Use of Smartphones and Tablets. Pediatrics 2020, 146, e20193518. [CrossRef]

68. Alturki, H.A.; Brookeses, D.S.; Davies, P.S. Does spending more time on electronic screen devices determine the weight outcomes in obese and normal weight Saudi Arabian children? Saudi Med. J. 2020, 41, 79-87. [CrossRef] [PubMed]

69. Wiecha, J.L.; Sobol, A.M.; Peterson, K.E.; Gortmaker, S.L. Household Television Access: Associations with Screen Time, Reading, and Homework Among Youth. Ambul. Pediatr. 2001, 1, 244-251. [CrossRef]

70. Pyper, E.; Harrington, D.; Manson, H. The impact of different types of parental support behaviours on child physical activity, healthy eating, and screen time: A cross-sectional study. BMC Public Health 2016, 16, 568. [CrossRef] [PubMed]

71. Dolatabadi, N.K.; Eslami, A.A.; Mostafavi, F.; Hassanzade, A.; Moradi, A. The relationship between computer games and quality of life in adolescents. J. Educ. Health Promot. 2013, 2, 20. [PubMed] 
72. Krist, L.; Roll, S.; Stroebele-Benschop, N.; Rieckmann, N.; Müller-Nordhorn, J.; Bürger, C.; Willich, S.N.; Müller-Riemenschneider, F. Determinants of Physical Activity and Screen Time Trajectories in 7th to 9th Grade Adolescents-A Longitudinal Study. Int. J. Environ. Res. Public Health 2020, 17, 1401. [CrossRef] [PubMed]

73. Roberts, D.F.; Foehr, U.G.; Rideout, V. Generation M: Media in the Lives of 8-18 Year-Olds; Henry J. Kaiser Family Foundation: Washington, DC, USA, 2005.

Publisher's Note: MDPI stays neutral with regard to jurisdictional claims in published maps and institutional affiliations.

(C) 2020 by the authors. Licensee MDPI, Basel, Switzerland. This article is an open access article distributed under the terms and conditions of the Creative Commons Attribution (CC BY) license (http://creativecommons.org/licenses/by/4.0/). 